\title{
Some Urgent Issues of Georgia's Geography
}

\author{
Nodar Elizbarashvili ${ }^{1, ~ *}$, Giorgi Meladze ${ }^{1}$, Maia Meladze², David Svanadze ${ }^{1}$, Lizi Gadrani ${ }^{3}$, \\ Josef Lazarashvili ${ }^{3}$ \\ ${ }^{1}$ Ivane Javakhishvili Tbilisi State University, Faculty of Exact and Natural Sciences, Department of Geography, Tbilisi, Georgia \\ ${ }^{2}$ Institute of Hydrometeorology at the Georgian Tecnical University, Department of Climatology and Agrometeorology, Tbilisi, Georgia \\ ${ }^{3}$ Vakhushti Bagrationi Institute of Geography at Ivane Javakhishvili Tbilisi State University, Department of Geomorphology and Geoecology, \\ Tbilisi, Georgia
}

\section{Email address:}

nelizbarashvili@yahoo.com (N. Elizbarashvili),meladzeg@gmail.com (G. Meladze)

\section{To cite this article:}

Nodar Elizbarashvili, Giorgi Meladze, Maia Meladze, David Svanadze, Lizi Gadrani, Josef Lazarashvili. Some Urgent Issues of Georgia's Geography. Earth Sciences. Special Issue: Modern Problems of Geography and Anthropology. Vol. 4, No. 5-1, 2015, pp. 1-7.

doi: $10.11648 /$ j.earth.s.2015040501.11

\begin{abstract}
Geography is facing new challenges in Georgia. On the one hand, it is related to evaluation of current condition of the country and its geo-ecological issues, and on the other hand, the requirements of practice and the prospects of socio-economic development. The requirements of practice imply several urgent issues such as new orientation of the land use and the optimal use of the region's natural-resource potential, demographic stability and development of mountainous areas. The prospects of the country's development include the urgent issues such as global environmental problems and prediction of geo-system conditions, development of military geography and planning of environmentally strained areas. In order to present and solve these problems effectively, Georgian School of Geography should play a key role, which will become a prerequisite for its further development.
\end{abstract}

Keywords: Georgia, Geography, Landscape Planning, Tourism

\section{Introduction}

The study of the current geographical issues is related to integration of separate components and directions of geography, creation of GIS databases and their promotion. The organizational prerequisite for integration already exists in the form of academic geographical education and the unification of academic geographical science [1, 2, 3, 4, 5, 6, 7].

The expected environmental changes, such as a hard demographic situation, revision of economic specialization, geopolitical challenges, large-scale transportation projects and the prospects of international cooperation, require consolidation of the Georgian School of Geography. We believe that this is the only way, which can help to develop and integrate it within the social processes [8].

Global warming and the processes associated with it are evident throughout the world, it has already affected the life of the communities and in many cases it has a negative impact. Georgia is not an exception in this regard. The global warming forecasts vary all over the world. Its development may result in the change in the air temperature and precipitation distribution, reduction of the potential of the mountain resorts' natural-resources, extinction of a number of plants and animal species, change in water regimes, movement of landscapes, decline in vital environment and population migration.

The Landscape planning is a new practical-theoretical scientific direction, which does not have a long history in Georgia. It is committed to develop and distribute the information on the current state of the landscapes, the forms and scale of anthropological impact, sustainability, potential, social and socio-economic functions. Its development is related not only to solution of the problems of the regional nature use, but also to development of certain methodological grounds (depending on the specifics of the mountainous areas). The landscape planning is the multifaceted scientific task, which consists of several stages. It includes inventory, assessment, forecasting and development of a system of environmentally oriented measures. The implementation of the measures may be of small, medium and large scale, which will regulate the implementation of the scientific and practical measures to ensure the reliability of Landscape Planning [9].

One of the key and urgent issues of Landscape Geography is to define the landscape functions. It is understood that this activity requires participation of a number of specialists of different fields, who will consider the ecological and ethological features of the landscapes. Desirably, it should be 
based on landscapes certification, which should include the information on the geographical peculiarities of the population and the economy, social conditions within the landscapes, etc.

Georgia, by virtue of ongoing geopolitical changes and the challenges in the region, is at the most important stage of its development. The national development of the country and its integration into the Euro-Atlantic space requires solution of a range of problems, among which the most important is to ensure the safety of military and defense capabilities. The rapid development of the national military should be firmly based on the military and social, natural or technical sciences related thereof. Their integration has a great importance for successful implementation of military reforms. Geography is one of the major directions related to the military field.

For the Military Geography it is important to analyze the components of physical and economic, social, ethnic, cultural and political settings. The settings are reviewed from the local and regional perspectives. They often determine: the range of military actions, strategy and tactics of military actions, structure and composition of armed forces, directions of military education and other areas. From the military-geographical point of view, it is essential to study the socio-economic indicators, such as: 1 . The number of population, density, age and religious structure, migration, etc.; 2. Economy development tendencies, deployment of military industry and energy industries, etc.; 3. The Geographical features of transportation and communications objects (roads, bridges, pipelines, railways, ports, etc.) and facilities; 4. Layout and density of settlements. It is noteworthy that this information has been thoroughly explored in Georgia. However, it has not been evaluated in terms of military-geographical context yet [10].

In the early1990s, the armed conflicts, which took place in Tskhinvali region and Abkhazia and catastrophically deteriorated social and economic situation, had a negative impact on the country's demographic system. The natural relocation of the population sharply declined, the number of emigrants accounted for more than a million people. The processes led to the demographic crisis, which proved to be particularly hard for the mountainous regions, a number of which belongs to the demographically declining regions.

After the collapse of the Soviet Union, Georgia's geopolitical location acquired a completely new meaning. This event made it relevant to distinguish the geographical units according to the modern requirements, which stand out by both the separate geographical segments and components, and landscape and ethno-geographic diversity.

\section{Results and Discussions}

\subsection{Global Warming}

Climate change is mainly associated with the pollution of the atmosphere and hydrosphere, deforestation, desertification and rise of the world sea level. The debates over the climate change persist. On the contrary, it has become the subject of not only science, but also of political interests. It is known that the expected consequences of climate change are regarded as the issue of global environment and also economic and social problem.

We will discuss some of its consequences, which were observed in the separate regions of the world and in Georgia.

- The climate change in the Northern Hemisphere has become noticeable since the beginning of 20th century. The warming in the 1930s of the previous century (average air temperature increased by $0.60^{\circ}$ ) was followed by non-essential cold in the 1950s of the same century, and then (in the 1960s) again by warming. There are two explanations for global warming. The first is associated with the greenhouse effect, and the other - 11 and 80-year cycles of the solar activity. It is estimated that in Georgia for the last century, the average temperature increased by $0.6 \mathrm{C}^{\circ}$.

- The signs of global warming have become alarming since the 1980 s of the 20 th century. It was observed that the average air temperature on a number of islands in the Arctic Ocean (Greenland, Spitsbergen, New Land) and in the coastal areas increased by $2-3^{\circ}$ for the period of one century. In Iceland, the areas, which were used to grow annual crops 600 years ago, were released from ice cap. A rapid reduction of ice cap was observed in Alaska and Greenland, as well as in the mountainous systems of all of the temperate zones. In Georgia, namely, in the glacial-nival zone of the Caucasus, the increase in glaciers is obvious - due to shredding of large glaciers and decrease in their total area.

- In addition to reduction of the ice-covered areas, in the northern hemisphere, the eternal permafrost and the process of movement of the lower border of tundra and taiga to the north are observed. The same signs have been identified in the mountainous areas of the Caucasus, which is reflected in the decline of the upper border of subalpine forests [11];

- In the arid regions of the northern hemisphere, the amount of atmospheric precipitation reduced, especially during the cold seasons. The mentioned event was followed by the loss of river flow and the reduction of water level in the water reservoirs. The scale, intensity and also the number of droughts increased and it became the reason for degradation of the vital environment and delay in the economic activities in a number of regions. Over the recent decades, the most significant decrease in the amount of precipitation (10\%) has been observed in the tropical climate of North Africa and South-east Asia. Some anomalies have been also identified increase of rainfall in Australia's west coast, whereas on the east shores we are dealing with the opposite phenomenon. It was estimated that in the east areas of the steppe landscapes of Georgia, the share of areas covered with semi-desert vegetation is increasing;

- The thermal regime of almost all the regions of the world and its geographical features show that the nowadays global warming is observed everywhere, in various degrees though. The maximum climate change was observed on the land, in the temperate zones between the $40-70^{\circ}$ of the North Latitude. The frequency of extreme weather indices has also increased. Over the recent years, Georgia has witnessed extremely high temperatures in the areas, where they have never been 
identified;

- The variability of climatic characteristics on the oceans is comparatively less, and in some areas negative anomalies are also observed. But the impact of global warming is still visible in the world ocean - its level has increased by $10-25 \mathrm{~cm}$ over the past 100 years. This situation, first of all, is associated with the ice melting global trends. The same happens along the Black Sea coastline, Georgia;

- Global warming has also been revealed by length and thickness of snow cover. Its indicators declined on Eurasian and North American continents. The situation is same in Georgia, where almost all (the length, thickness, and geography) the indicators of snow distribution have changed over the past half-century.

The climate change tendencies are discussed in the research "The Second National Communication to Framework Convention on Climate Change", which was developed under the joint project of the Ministry of Environment and Natural Resources Protection of Georgia and the United Nations Development Program [12]. According to the project, the processes and tendencies related to climate change were linked to a number of geographic settings, out of which the major is the air temperature, precipitation and moisture degree. Their analysis made it possible to evaluate the tendencies of climate change, as well as the quantitative and spatial and temporal features of extreme weather development. The analysis was carried out using the statistical methods based on the data provided by the National Environmental Agency of Georgia, which includes the period from the mid of XX century until 2007. In addition, by the year of 2100 the key climatic parameters will be evaluated based on two global climate models for Georgia in general and for its three regions (the Black Sea coastline - Poti weather station, the Great Caucasus - Lentekhi weather station and the intermountain plain - Dedoplistskaro weather station). For each parameter, the tendencies of change are assessed according to the year and season criteria.

In accordance with the National Communication, over the previous half century, the territory of Georgia has been marked by the increase (especially in the recent decades) in precipitation and the average annual rates of air temperature, as well as the "warming" of bare minimums (except Dedoplistskaro) and bare maximum within the three priority regions (Poti - $13 \%$ of precipitation, $\mathrm{t}-0.2^{0} \mathrm{C}$, Lentekhi - $8 \%$ of precipitation $\mathrm{t}-0.4^{0} \mathrm{C}$, Dedoplistskaro $-6 \%$ of precipitation, $t-0.6^{\circ} \mathrm{C}$ ). The analysis of the change in the amount of precipitation gives a comparatively different picture for the East and West Georgia. In this case, West Georgia is marked by its annual downward trend $(27 \mathrm{~mm})$, and increase in $41 \mathrm{~mm}$ in East Georgia.

According to the Second National Communication, which is based on the global models and scenarios, in the light of global climate change, the following is expected by the year 2100 :

- In West Georgia, the average annual air temperature will increase by $3.5^{\circ} \mathrm{C}$ (or $38 \%$ ) and will reach $12.6^{\circ} \mathrm{C}$. The amount of average annual precipitation will decrease by 70 $\mathrm{mm}(9.4 \%)$ and will amount to $1127 \mathrm{~mm}$;
- In East Georgia, the average annual air temperature will rise by $4.1^{\circ} \mathrm{C}$ (or $26 \%$ ) and will reach $15.4^{\circ} \mathrm{C}$. The amount of average annual precipitation will decrease by $83 \mathrm{~mm}(8.5 \%)$ and will amount to $487 \mathrm{~mm}$.

\subsection{Landscape Planning}

In most European countries, landscape planning is considered as an effective tool of sustainable development. The European experience in landscape planning has greatly contributed to the development of a unified system of territorial planning in Europe, and ultimately, the integration of the European countries. Nowadays, not only the EU countries, but also the post-Soviet regions and states are involved in this activity. The integration processes are particularly active in Russia, the Baltic and South Caucasian countries. Some steps have already been taken in Turkey and Iran, which is an important prerequisite for the regional cooperation. The countries of the European Council consider the above mentioned states as important partners in case of implementation of the instruments and principles of landscape planning. Due to this, Georgia should timely introduce the international standards for nature use and territorial planning.

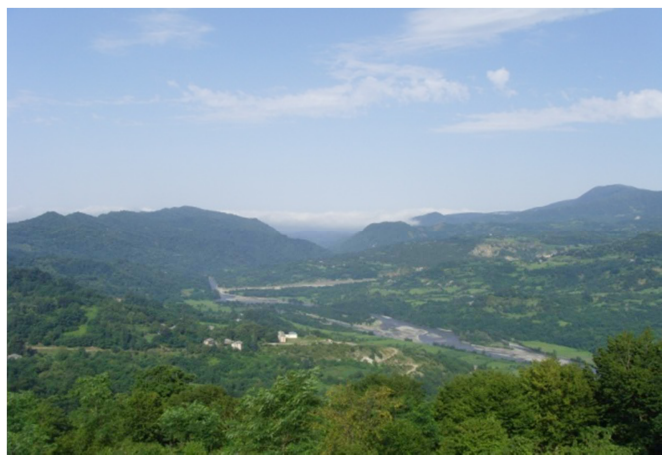

Figure 1. Humid landscapes of West Georgia.

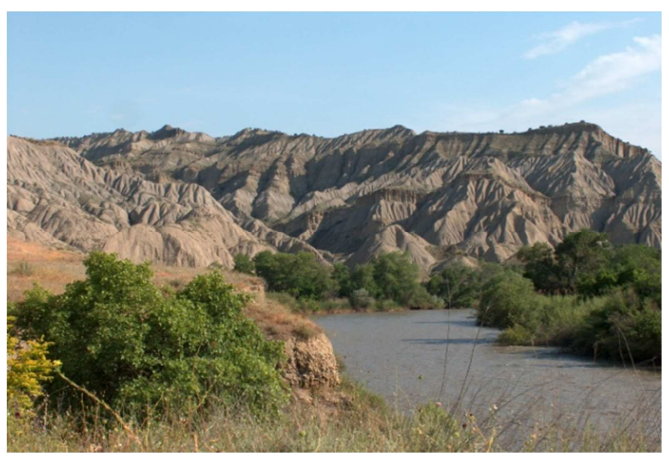

Figure 2. Semi-arid landscapes of East Georgia.

Introduction of the landscape planning principles and instruments in Georgia shall not imply the direct copying of the European experience [13]. Our country's current socio-economic and geo-ecological conditions require a relevant approach during the process of developing the special tools for landscape planning. They are as follows:

- A certain part of Georgia's territory (almost $1 / 10$ ) is represented by natural landscapes, and this is an 
important prerequisite for development of recreational facilities, protected areas, specific forms of nature use and a number of scientific directions;

- The formation of a new network of the Protected Areas in Georgia is being implemented quite rapidly, which should take into account the vital interests of the local population and the country's sustainable development;

- Georgia is a country of small landowners and high geo-ecological risks, and this determines the specificity of landscape planning and orientation;

- The mountainous areas of Georgia are characterized by high population migration and depopulation, which ultimately affects the sustainable development of the regions and exacerbates the social situation;

- Currently, Georgia does not possess large financial capabilities to deter the large-scale use of natural resources or fully implement environmentally oriented territorial planning. However, in any case, the principles of sustainable development, and balanced and comprehensive plans should be considered during the process of regional planning. For this reason, it is possible to integrate the landscape plans into the development plans of different scale (level).

- The socio-economic condition in Georgia largely determines the degradation of the environmental thinking, which leads to a low ecological culture. The imperfect environmental legislation, often of controversial nature and the lack of relevant experts in the field makes it even more complicated. It should be noted that the community is not involved in the territorial planning process.

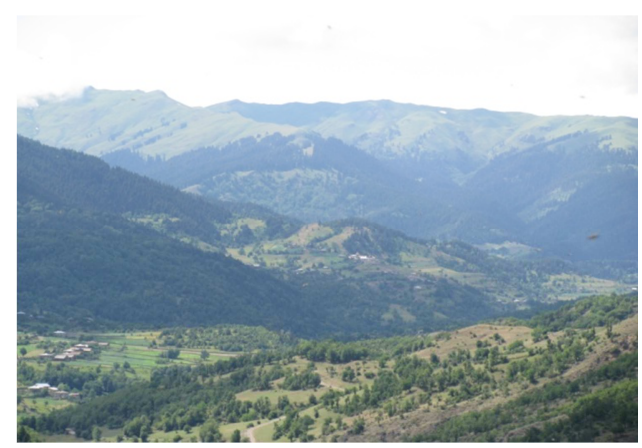

Figure 3. Semi-humid landscapes of southern Georgia.

Presently, Tbilisi landscape planning has been added to the agenda, which is related to several topical issues. Our capital city was under constant development for hundreds of years, but its significant growth started in the late 20th century. For several decades, the population of Tbilisi increased by 2.5 times, and its area by 5 times. The growth of the city's population was mainly due to internal migration. The trend of artificial growth of Tbilisi population is still maintained. Such aggregation of the population results in some issues especially, exacerbation of environmental situation and the problems thereof. The "green" zones within the city are significantly reduced, the air and water is polluted, and the recreational areas outside the city are being redesigned. Development of new territories within Tbilisi borders, which has been carried out for several years, leads to transformation of the city's natural environment and the intensive use of resources. The situation is exacerbated by the fact that the ecological situation of the city, the natural conditions and potential, development of suburban and recreational economies are not taken into consideration. This attitude, in the light of global warming, may lead to growth of the city's environmental problems.

The implementation of the European methodology of landscape planning for Tbilisi functional zones and its development is very important from both scientific and practical point of view. It is known that landscape planning is directly linked to territorial land use and socio-economic planning; it considers the requirements of the community and local population regarding the socio-economic and ecological functions of landscapes; primarily, it is of geological profile and is focused on preservation of species and biotypes, landscape and biodiversity; it takes into account the peculiarities of historical and cultural development of the area, and due to which in some cases it has not only the ecological direction, but also the function of restoration the landscape (scenery) aesthetic condition and its maintenance;

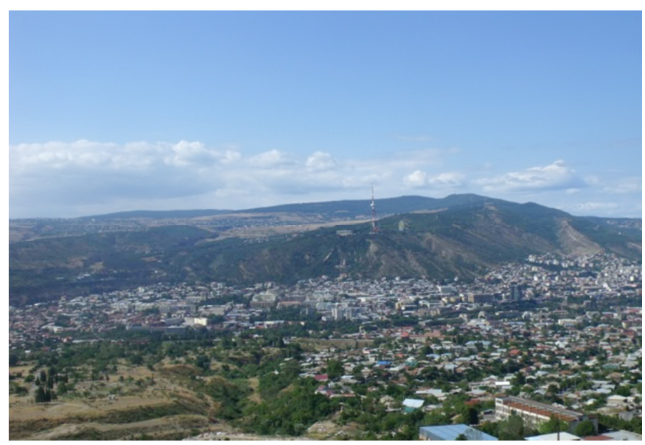

Figure 4. Landscape view of Tbilisi.

The results of Tbilisi landscape planning are important for sustainable development, particularly, for development of ecological stability, urban and recreation economies.

To achieve the aforementioned goals, the following key tasks should be implemented: to obtain the geological, geo-morphological, climate, hydrology, bio-geographic, landscape-ecological, demographic and environmental information on Tbilisi landscapes and analyze it; to carry out field-geographical and environmental research on Tbilisi landscapes; to create the electronic database and GIS mapping of Tbilisi landscapes; to evaluate Tbilisi landscapes and functional zoning; to implement landscape planning of Tbilisi using the GIS methods.

Implementation of the tasks above, together with the findings of the research, should preferably become the grounds for a large-scale urban and landscape planning in Georgia, and the basis for development of scientific and practical activities.

The results of Tbilisi landscape planning will provide the grounds and motivate a variety of organizations and agencies engaged in the nature use, planning and economic activities, encourage teaching processes at high schools, the regional and 
local government organizations, non-government environmental organizations etc. The results obtained through the process of Tbilisi landscape planning, based on the national concept on ecological security, will enable us to develop the basics of sustainable development and landscape planning for other cities and regions of Georgia.

\subsection{Landscape Functions}

The modern functions of landscapes clearly reflect the level of community development. In the developing countries, the landscapes mostly «meet» the requirements of the society (the resource production function), whereas in the developed countries, they "take into account» the requirements of the society, as well as the ecological purpose, potential, and sustainability of the landscape, etc.

The landscape may simultaneously perform one or more functions which vary depending on the requirements of a society and geo-ecological conditions. Such changes, above all, should be carried out by considering the potential abilities of the landscape. In the highly urbanized European states, the landscape has a multipurpose task, which is regulated as a state policy and is regarded as a major direction of the territorial planning.

The landscape functions are the dynamic indicators, i.e. they change in space and time. The change, ultimately, must lead to optimal use of landscape functions. The topical issues of landscape geography are to identify, classify and define the landscape functions.

Since the 1980s of 20th century, the sustainable socioeconomic development and ensuring healthy environment has become the fundamental principle of the entire civilized world. It includes the equalization of living standards as well as the maintenance of the ecological balance. The latter shall be carried out by means of environmentally oriented territorial or landscape planning.

The European experience in landscape planning (German) is being widely implemented in the research and planning agencies of the post-Soviet states (Russia, the Baltic States, South Caucasus, Central Asian States). Its methodology enables to develop and disseminate the information about the current state of the landscapes, forms and scale of anthropological impact, potential, sustainability and functions. However, the European Landscape Planning Methodology [14] does not include the peculiarities of the mountainous areas. Therefore, it is essential to provide the guidelines for implementation of a "green plan" and the methodology for resort or agro-landscape planning. These issues represent the topical issues of the Landscape Geography.

The landscape planning is closely linked to landscape etiology, which was founded as a scientific direction at Georgian School of Geography by Professor N. Beruchashvili. It discusses the key characteristics, such as daily, decadal, monthly, annual and multiyear conditions, dynamics, and transitional and critical conditions, balance, natural regime, development (evolution), etc. of landscapes.

Every year, hundreds of scientific studies are dedicated to landscapes etiology. It is obvious that the list of the issues associated with the landscape etiology may be extended further, but in the end, we will basically deal with the relevance of research on landscape structure and space-time cycle of its functions, and assessment of subsequent natural and anthropogenic regimes. It is linked to a number of topical issues of landscape etiology, among which, in our opinion, the landscape functions and the landscape (territorial) planning are closely related.

\subsection{Military Geography}

Actually, the talks about the necessity of development of the Military Geography in Georgia have just begun due to the historical processes, which took place in our country over the last two centuries. During that period, Georgia did not carry out the military construction independently. So far, the military-geographical evaluation of the Georgian territory has not been carried out yet; moreover, there is hardly any specific literature in Georgian language and relevant experts of military-geographical specialization [10].

The Military Geography among the geographical sciences is considered as the part of the social and physical geography, i.e. the unified geography. The military geography aims to study strategy, tactics and the capabilities of the military actions in various geographical settings. The aim includes the tasks of the military geography as well. They are related to analysis and evaluation of social and natural systems, facilities, events and processes in order to fulfill military objectives (tactical, operational and strategic). The military geography helps to evaluate the geographical characteristics the consideration of which carries a particular importance to development and successful accomplishment of military operations.

The military actions are influenced by geographical objects, events and processes. The history of military operations is full of the facts when in consideration of the environment conditions caused the greatest damage to the divisions involved. The greatest importance of geographical factors while planning and conduction of the military operations is recognized by military specialists and the theorists $[10,15]$.

The military-geographical information is a time and space variable category, from which the geopolitical and social processes are characterized by exceptional dynamism. Martial art and military equipment are also rapidly developing due to which the military-geographical analysis and evaluation need to be constantly updated.

\subsection{Geo-demographic Issues of Georgia's Highlands}

The current geo-demographic crisis in the mountainous region of the Caucasus poses new challenges to the Georgian School of Geography. The living standards of the population in the mountainous regions are sharply deteriorated and a number of regions were placed in the category of "Dying Regions" in terms of demography. Although in 1999 the law was passed "On Social, Economic and Cultural Development of the Mountainous Regions", the situation still got worse. Actually, the communications in the mountainous regions are out of order, the traditional industries are gradually lost, the 
danger of losing the cultural heritage has become a reality, etc. The crisis is evident, although there are various theories and endless discussions on the ways of its recovery. The situation requires the immediate research of the problems, formation of a new understanding and solution.

One of the important instruments, which may be used to improve the demographic situation in the mountainous region of Georgia, is the theory and methodology of central places, which is well-known in geography. It includes the methodology of settlements, which may provide social services and economic development for the surrounding areas. This approach is highly effective for the mountainous areas and the regions distinguished by negative demographic processes. The methodology allows us to determine the settlements within the Caucasus region which will "take up" the function of the central part and prevent the migration process from the mountainous regions.

\subsection{Tourism}

Tourism is rightly considered as one of the main directions of socio-economic development of Georgia. The majority of the world-famous resorts and recreational resources are located in Georgia as well. Georgia has many perspectives in different fields like development of national tourism recreation trans-boundary tourism, development of transboundary protected areas etc. [16]. The natural diversity influences on cultural diversity and nature management types as well. Georgia in inhabited by different national and religious groups that have influenced on the nature management forms, which are quite differently expressed in different regions of Georgia [17]. Moreover, given the fact that these resources are located in a small area, our country can be considered as the richest and unique state in the world. This potential can promote the development of various forms of tourism in our country including the development of scientific tourism, both theoretical and practical directions.

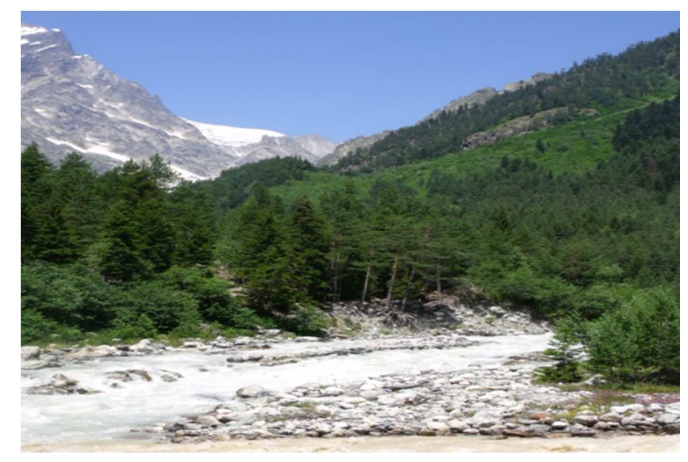

Figure 5. Mountain landscapes of northern Georgia.

The Georgian geography literature includes few works on scientific tourism, which could fully demonstrate its essence, the structure, the place in the scientific system, the research object and the subject. In a great number of publications dedicated to tourism, the scientific tourism is referred to as a direction of the field, but there is no mention on the specifics of the methodology or its practical importance. In Georgia, the development of the theoretical and practical basis of scientific tourism is one of the topical issues of geography development.

\subsection{Geographical Units}

The geographical units are the areas where three or more homogeneous geographical features are located closely to each other. The geographical units can be discussed according to their forms: simple, average, difficult and complex), and types: component-geographical, sectoral-geographic, geographical $[18,19]$.

The identification of social and geographical units is related to certain difficulties. In this direction of geographic science a number of spatial features of social processes, their approach or crossing areas already have their own names (agglomeration, metropolis, industrial units, transportation hubs, and so forth). The social and geographical units are mainly characteristic to lowlands. The physical -geographical units are the areas distinguished by landscape and biodiversity, however, the same does not apply to social -geographical units which acquire characteristic properties of the borderline areas. It is of great importance to determine the ethnic units, which include the national composition of the population and the historical and geographical features of their distribution.

\section{Conclusion}

By the end of the 21 st century, tendencies in climate change will be most visible in the lowland landscapes of East Georgia. Currently, almost half of Georgia's population, i.e. 2 million inhabitants lives there. Shida Kartli lowland, Kvemo Kartli lowland and Kakheti hilly part are characterized by a high density of population. Here is Tbilisi as well, the capital of Georgia, which is marked by the infrastructure development and the environmental variability hardly affects it.

The landscapes of Georgia, which are heavily affected by the consequences of global warming, are as follows:

1. Kvemo Kartli lowland semidesert landscapes. The area is $370 \mathrm{~km}^{2}$; the current amount of precipitation totals $400 \mathrm{~mm}$, the population is more than 500 thousand inhabitants. The area is under the danger of desertification unless the irrigation system is developed;

2. Shida Kartli lowland steppe landscapes. The area is 560 $\mathrm{km}^{2}$; the current amount of precipitation totals $500 \mathrm{~mm}$, the population is more than 150 thousand inhabitants. The area is under the danger of semi-desertification unless the irrigation system is developed;

3. Iori Upland steppe landscapes. The area is $1140 \mathrm{~km}^{2}$; the current amount of precipitation totals $550 \mathrm{~mm}$, the population is more than 50 thousand inhabitants. The area is under the danger of semi-desertification unless the irrigation system is developed;

4. Iori Upland steppe landscapes of the southernmost part. The area is $170 \mathrm{~km}^{2}$, the current amount of precipitation totals $400 \mathrm{~mm}$, the number of permanent and seasonal population is up to 5 thousand inhabitants. The area is under the danger of semi-desertification unless the irrigation system is developed;

5. The semi-desert landscapes of the extreme south-eastern 
part of Georgia. The area is $90 \mathrm{~km}^{2}$, the current amount of precipitation totals $350 \mathrm{~mm}$, no permanent inhabitants [20]. The mentioned landscapes may become a desert.

Thus, according to the global warming and its expected consequences, the problem of eco-system change and its degradation threatens almost $3.5 \%$, i.e. $2330 \mathrm{~km}^{2}$ of Georgia's territory. The preventive actions must be implemented in order to deter the processes. Otherwise, more than 700 thousand people, i.e. $16 \%$ of the current population of Georgia, are under the danger to become ecological migrants.

The development of Military Geography in Georgia requires solution of several very important issues, namely, it is necessary:

1. To develop and publish the basics of Military Geography methodology (theoretical) in Georgian language in accordance with the NATO standards. We believe, that pursuant to the methodology, the elements of environment (relief, vegetation, water facilities, soils, meteorological elements, natural disasters, communications networks, composition of population, economic profile, etc.), which have a special importance for military operations, should be identified. The "Georgian" methodology should also include the international experience and the specifics of the mountainous areas;

2. To carry out the military-geographical analysis and evaluation of Georgia's territory. The basins of Landscape Rivers should be considered as basic units;

3. To develop the military-geographical database banks and GIS system of Georgian landscapes (river basins);

4. To develop appropriate guidelines and implement master's and doctoral programs.

In order to control the severe demographic situation in the mountainous regions of Georgia, it is necessary to pay serious attention to the socio-economic and cultural development of the region, without which it is impossible to achieve the desired settings and to retain population locally.

The existing mineral, landscape, recreational and other resources should be used reasonably and purposefully, which will contribute to rise of the economic potential of the region and improve the social conditions of the population. We believe that introduction of a special tax may also improve the economic situation.

Due to Georgia's geopolitical location, it is important to determine the geographical units and explore their characteristics - in order to establish a network of Protected Areas, transport arteries and settlements, develop tourism, evaluate the historical formation of the region, implement the demographic policy, and plan different fields of the economy. It is necessary to develop a methodology for their gradual detachment, mapping techniques etc.

\section{References}

[1] E. B. Alaev. Economic and geographic terminology. Moscow, 1977. In Russian.
[2] E.B. Alaev. Socio-economic geography. dictionary. M., 1983.

[3] N.L Beruchashvili,. Diversity of Georgia's landscapes and geographical analysis of landscapes diversity of the world. Proc. of the First National Conference: biological and landscape diversity of Georgia. Tbilisi. 2000. in Russian

[4] A.G. Isachenko. Landscape studies and physical-geographical zoning. Moscow, 1991. In Russian.

[5] The study of environmental conditions. Tbilisi, 1982.

[6] Protection of landscapes. dictionary. Moscow, 1982. In Russian.

[7] V.S. Preobrajensky. Search in Geography. Moscow, 1986. In Russian.

[8] N. Elizbarashvili. Geoecological essentials of landscape planning. Tbilisi, 2005. p.35. In Georgian.

[9] Landscape planning: metodology and experience. Edited by N.Elizbarashvili. Tbilisi-Bonn-Irkutsk, 2009. p.43.

[10] N. Elizbarashvili, G. Dokhnadze, G. Lefonava, G. Meladze, D. Svanadze, T. Tchavtchanidze, E. Tsereteli, N. Moseshvili, Z. Laoshvili, B. Kalandadze, T. Dekanoidze. MIlitary Geography of Georgia. Tbilisi, 2012. p.63.

[11] Biological and Landscape Diversity of Georgia. Proceedings of the First National Conference. -Tbilisi, 2000. p. 312.

[12] Georgia's second national communication to the UNFCCC 2009, Tbilisi.

[13] European Landscape Convention. Opening for signature on 20 October 2000, European Treaty Series - No.176, 9 p. Florence. Http://conventions.coe.int

[14] Piloting Landscape Planning in The Countries of the Southern Caucasus- Baku-Tbilisi-Erevan. Publish by TJS-Caucasus, 2009, p. 121.

[15] G.Dokhnadze, L.Dokhnadze. State problems of Georgia in the military geography. TSU, 2005. In Georgian.

[16] D. Nikolaishvili, V. Trapaidze, B. Kalandadze, T. Mamukashvili, M. Sharashenidze. Complex Evaluation of Climate Change - An Example FROM THE Georgia's Landscapes. Journal of Environmental Biology, 2015. vol. 36. Special issue, January, 2015. pp.43-49. http://www.jeb.co.in/journal_issues/201501_jan15_supp/paper _07.pdf

[17] D. Nikolaishvili, D. Sartania, L. Matchavariani. Complex Evaluation of Different Factors on Growth of Grape in Georgia. Dali International Conference "Applied Ecology: Problems, Innovations". Proceedings ICAE-2015. 7-10 My, 2015. Tbilisi-batumi. pp. 292-296.

[18] N. Elizbarashvili N. Essentials of Geography. Tbilisi, 2012. In Georgian.

[19] N. Elizbarashvili, L. Matchavariani, D. Nikolaishvili, G. Meladze. Landscape planning of Pshav-Khevsuteri protected areas. Tbilisi, 2012. In Georgian.

[20] D. Nikolaishvili. Spatial-temporal analysis of Georgia's landscapes. Tbilisi, 2009. In Georgian. 